\title{
DESENVOLVIMENTO, AVALIAÇÃO SENSORIAL E FÍSICO-QUÍMICA DE BARRA DE CEREAL DE CAJU
}

\section{DEVELOPMENT, SENSORY AND PHYSICAL-CHEMICAL CHARACTERISTICS OF CASHEW APPLE CEREAL BAR}

\author{
Catiana Freitas Pinto de Oliveira ${ }^{1}$; Hélia Lucila Malta ${ }^{2}$; Maria Antonia Carvalho Lima de Jesus ${ }^{3}$; Renato \\ Souza Cruz; Flávio Souza das Neves Cardoso ${ }^{4}$ \\ ${ }^{1,2,3}$ Universidade Estadual de Feira de Santana - UEFS - Feira de Santana - Brasil catianafreitas@ gmail.com \\ ${ }^{4}$ Universidade Federal do Rio de Janeiro - UFRJ - Rio de Janeiro - Brasil fláviosnc@gmail.com
}

\begin{abstract}
Resumo
A associação de barra de cereais com o caju tem se mostrado uma tendência inovadora que visa atender às demandas mercadológicas e evitar o desperdício de uma fruta tão nutritiva. Logo, o objetivo do presente trabalho foi elaborar e avaliar as características sensoriais e físico-químicas de uma barra de cereal enriquecida com a fibra do bagaço do caju. Através dos testes de aceitação pode-se verificar uma boa aceitabilidade da barra de caju por parte da maioria dos julgadores, os quais se mostraram propensos a comprá-la. As análises físico-químicas revelaram que a barra de caju pode ser um alimento com alto teor de vitamina $C$. Os resultados são de grande interesse para as agroindústrias, uma vez que abre uma nova possibilidade de um produto a ser lançado no mercado consumidor, além de garantir o aproveitamento do pedúnculo do caju através de um produto com características sensoriais e nutricionais desejáveis.
\end{abstract}

Palavras-chave: barra de cereais; caju; resíduos.

\section{Introdução}

No Nordeste a agroindústria do caju produz anualmente, cerca de 200 mil toneladas de amêndoas e 2 milhões de toneladas de pedúnculo (OLIVEIRA; ANDRADE, 2011).

O caju apresenta especial interesse nutricional e econômico pela qualidade de sua castanha (verdadeiro fruto) e pela riqueza em vitamina $\mathrm{C}$ e fibras de seu pedúnculo, o qual corresponde à polpa comestível (pseudofruto) (LIMA, 2004).

O pedúnculo do caju é uma matéria-prima abundante e de baixo custo para a indústria de alimentos, principalmente para produção de suco e polpas, porém é amplamente desperdiçado nas propriedades rurais, por ser uma fruta muito perecível, que exige cuidados especiais no manuseio e transporte (SOARES, 1986). O Brasil se destaca em ações que visam o aproveitamento do caju, 
contudo, estima-se que industrialmente sua utilização esteja em torno de apenas $20 \%$ ao ano (PINHO, 2009). O resíduo do processamento do caju geralmente é aproveitado para ração animal ou adubos. O custo de secagem, armazenagem e transporte do resíduo são fatores que economicamente limitam o seu aproveitamento (KABORI, 2005).

Por outro lado, o caju é notavelmente explorado pelo seu grande potencial vitamínico. A fruta apresenta teores de vitamina $\mathrm{C}$ que variam de 120 a 300mg/100g, valores considerados altos quando comparados às doses recomendadas para ingestão diária, que variam de 30 a $50 \mathrm{mg} / \mathrm{dia}$. $\mathrm{O}$ ácido ascórbico é importante por sua ação antioxidante e estimulação do sistema imunológico dentre outros benefícios à saúde que estão sendo investigados, tais como a inibição de compostos N-nitrosos causadores de câncer no estômago (LIMA, 2004). Perdas no teor de vitamina C, alterações sensoriais e reações de escurecimento devido à degradação do ácido ascórbico têm sido freqüentemente detectadas em frutos durante o processamento e o armazenamento (SOUZA FILHO et al., 1999).

As barras de cereais são formadas por grãos de cereais processados e aglomerados podendo ser adicionados ingredientes, tais como frutas desidratadas ou cristalizadas, sementes, castanhas, nozes, caramelos, chocolates, etc (CARVALHO, 2008). Possuem elevado valor nutritivo, além de favorecer uma alimentação com alto teor de fibras e elevado aporte energético e baixo teor de gorduras. Seu consumo cresce continuamente devido à conveniência e associação com alimentos saudáveis e de baixo teor calórico (GUTKOSKI et al.,, 2007; FREITAS, 2006).

Em barras de cereais, um dos ingredientes mais empregados é a fruta seca ou dessecada, obtida pela perda parcial da água da fruta madura, inteira ou em pedaços, por processos tecnológicos adequados. Os principais aspectos considerados na elaboração desse produto incluem a escolha do cereal (aveia, trigo, arroz, cevada, milho), o enriquecimento com vários nutrientes como as fibras alimentares, vitamina $\mathrm{C}$, etc. e também sua estabilidade desses ingredientes durante o processamento (O’CARROL, 1999 apud. BUENO, 2005).

Vários trabalhos têm proposto a utilização de diferentes matérias-primas, ou mesmo os resíduos do processamento destas, para produção de barras de cereais, dos quais se pode citar: Silva et.al. (2009) e Matsuura (2005) elaboraram uma barra adicionada do resíduo do maracujá; Lima (2004) elaborou varias formulações de barra de cereais contendo diferentes produtos derivados do caju; Bueno (2005) fez a incorporação de farinha de sementes de nêsperas nas formulações das barras; Coelho (2006) desenvolveu barras de cereais à base de amaranto; Carvalho (2008) incorporou casca de abacaxi na forma de pó em barra de cereais contendo diferentes tipos de amêndoas e Torres (2009) utilizou sementes cozidas de jaca na formulação da barra desenvolvida.

Através da associação de barra de cereal como alimento saudável e do aproveitamento do caju como fontes de vitaminas e fibras, conduziu-se o seguinte trabalho que tem por objetivo a 
elaboração e avaliação sensorial e físico-química de uma barra de cereal de caju. A utilização do pedúnculo de caju e/ou do seu resíduo industrial na elaboração de novos produtos pode contribuir na valorização da cultura do cajueiro em todo Brasil e ainda reduzir os impactos ambientais gerados pelo descarte destes resíduos em locais inadequados.

\section{Material e Métodos}

\section{Material}

Os cajus assim como os demais ingredientes utilizados no processamento das barras de cereais foram adquiridos no comércio local da cidade de Feira de Santana. O processamento do caju desidratado, do bagaço do caju e da barra de cereal foi realizado no Laboratório de Processamento da Universidade Estadual de Feira de Santana.

\section{Métodos}

Os cajus, antes de serem processados, foram submetidos ao descastanhamento manual, seleção (retirando-se os frutos estragados ou em estádio de maturação inadequado), lavagem em água corrente e sanitização com solução clorada a $200 \mathrm{mg} / \mathrm{l}$ e posterior enxágüe com água filtrada.

\section{Obtenção da fibra de caju desidratada}

A fibra de caju foi obtida mediante o despolpamento dos pedúnculos de caju em despolpador industrial ITAMETAL modelo COMPACTA com extração do suco, empregando-se prensagem de média pressão a fim de obter um material fibroso com um mínimo de teor aquoso. Fez-se uma trituração para reduzir o tamanho das fibras e realizou-se a secagem em estufa com circulação de ar forçada (POLIDRYER LTDA) a $60{ }^{\circ} \mathrm{C}$ durante 10 horas. A fibra já seca foi triturada novamente para obtenção de uma farinha de granulometria média e acondicionada em embalagens de polipropileno armazenadas a temperatura ambiente até o momento do uso.

\section{Obtenção do caju desidratado}

Os pedúnculos foram fatiados em fatiador BERMAR modelo BM 18 e submetidos à desidratação osmótica em solução de $30 \%$ sacarose e $0,5 \%$ de ácido cítrico, por uma hora. A desidratação foi realizada em estufa de circulação de ar forçada (POLIDRYER LTDA) a $60{ }^{\circ} \mathrm{C}$ até que as fatias de caju atingissem uma umidade de aproximadamente $10 \%$. As fatias foram trituradas em multiprocessador para redução do tamanho. 


\section{Obtenção da Barra de Caju}

Após vários testes de bancada, chegou-se à formulação da barra de caju (Tabela 1). Na elaboração da barra utilizou-se uma proporção de 50\% de ingredientes secos (farelo de trigo, aveia, flocos de arroz, fibra de caju desidratada, caju desidratado) e 50\% de xarope (xarope de glicose, sacarose, água, gordura vegetal, cremor de tártaro).

Tabela 1 - Formulação da barra de caju

\begin{tabular}{cc}
\hline Ingredientes & Percentual \\
\hline Secos & $\mathbf{5 0}$ \\
\hline Flocos de arroz & 15 \\
Flocos de aveia & 10 \\
Farelo de trigo & 5 \\
Fibra de caju & 5 \\
Caju desidratado & 15 \\
\hline Xarope & $\mathbf{5 0}$ \\
\hline Açúcar cristal & 24,7 \\
Glicose & 15 \\
Gordura vegetal & 4 \\
Água & 6 \\
Cremor de tártaro & 0,3 \\
\hline
\end{tabular}

O xarope foi misturado e concentrado em tacho aberto sob aquecimento brando, em seguida foram adicionados os ingredientes secos formando uma massa homogênea.Transferiu-se a massa para uma forma metálica onde as barras foram moldadas, cortadas e embaladas em embalagens de polipropileno armazenadas a temperatura ambiente até o momento do uso.

As barras de cereais de caju foram preparadas de acordo com as etapas apresentadas no fluxograma da Figura 1.

Figura 1- Fluxograma de obtenção das barras de cereais de caju.

Preparo do xarope
(xarope de glicose, açúcar cristal, água, gordura vegetal, cremor de tártaro)
$\downarrow$
Concentração até $82-83^{\circ}$ Brix
$\downarrow$
Adição da mistura dos ingredientes secos
$\downarrow$
(flocos de arroz, farelo de aveia, farelo de trigo, caju desidratado, fibra de caju)
Homogeneização
$\downarrow$
Deposição da massa em bandejas seguida de compactação
$\downarrow$
Corte
$\downarrow$
Retirada do molde
$\downarrow$
Embalagem em filme de polipropileno

\section{Análise Sensorial}

As análises foram realizadas no laboratório de Análise Sensorial da Universidade Estadual de Feira de Santana - BA. Foi oferecido um pedaço da barra equivalente a 15 gramas juntamente 
com água. O painel consistia de 50 julgadores não treinados pertencentes à comunidade local e universitária, na faixa de 18 a 50 anos de ambos os sexos.

O teste de aceitação foi usado para avaliar os atributos sabor do caju, textura e impressão global utilizando escala hedônica estruturada de nove pontos variando de 1 - "desgostei extremamente" a 9 - "gostei extremamente". Para a análise de intenção de compra foi usada escala de três pontos, onde os extremos correspondiam às opções "certamente compraria" e "certamente não compraria" e o termo médio correspondia à opção "talvez comprasse" (DUTCOSKY, 2007).

\section{Análise físico-química}

As determinações de umidade em estufa a $105^{\circ} \mathrm{C}$ até peso constante, teor de ácido ascóbico (INSTITUTO ADOLF LUTZ , 1985) e atividade de água (aparelho Decagon CX-2) das barras de caju foram realizadas em triplicata.Os resultados são a média das três determinações seguidos dos respectivos desvios padrões.

\section{Resultados e discussão}

\section{Análise sensorial}

A avaliação sensorial da barra de caju mostrou uma boa aceitação do produto frente à opinião dos julgadores, conforme os gráficos apresentados a seguir. O teste de impressão global, mostrado na Figura 2, indicou que $96 \%$ dos provadores gostaram do produto, dentre os quais: $24 \%$ gostaram muitíssimo, $38 \%$ gostaram muito, $14 \%$ gostaram pouco e $20 \%$ gostaram, os outros $4 \%$ indicaram não gostar nem desgostar do produto.

Quanto aos resultados da análise de intenção de compra (Figura 3), 100\% dos provadores se mostraram propensos a comprar a barra ( $74 \%$ certamente comprariam e $26 \%$ talvez comprassem).

Figura 2 - Impressão global das barras de caju

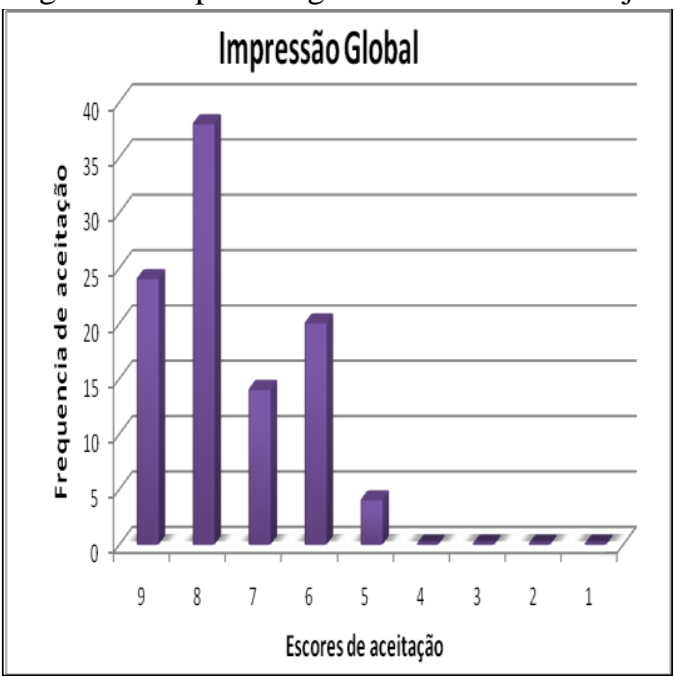

Figura 3 - Intenção de compra das barras de caju

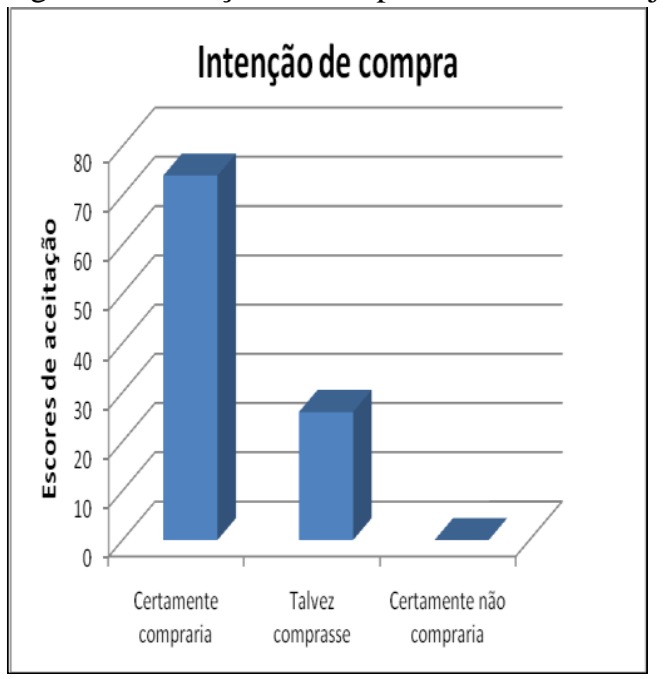


Quanto à textura da barra: 18\% gostaram muitíssimo, 48\% gostaram muito, 22\% gostaram, $10 \%$ gostaram pouco e apenas $2 \%$ não gostaram nem desgostaram, como pode ser observado na Figura 4. A Figura 5 ilustra a média de aceitação em relação ao sabor do caju onde $24 \%$ dos julgadores gostaram muitíssimo, 38\% gostaram muito, $22 \%$ gostaram, $10 \%$ gostaram pouco e $6 \%$ não gostaram nem desgostaram.

Figura 4 - Textura das barras de caju

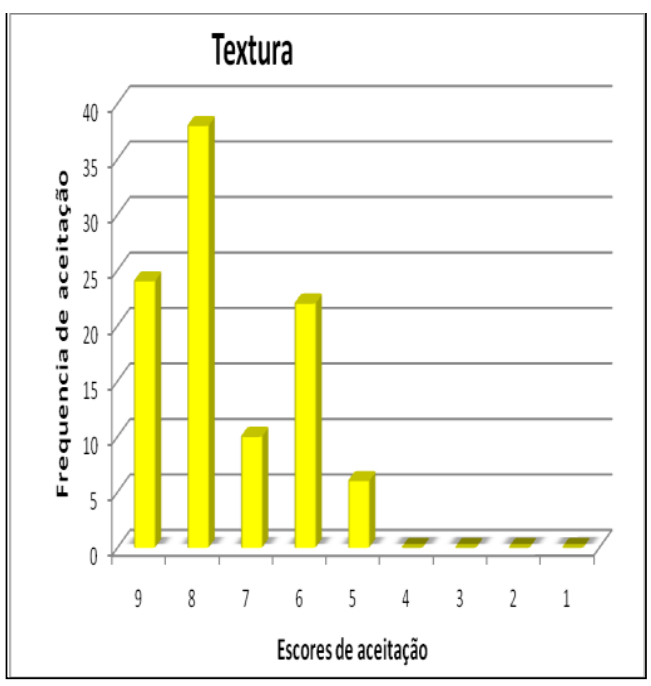

Figura 5 - Sabor caju das barras de caju

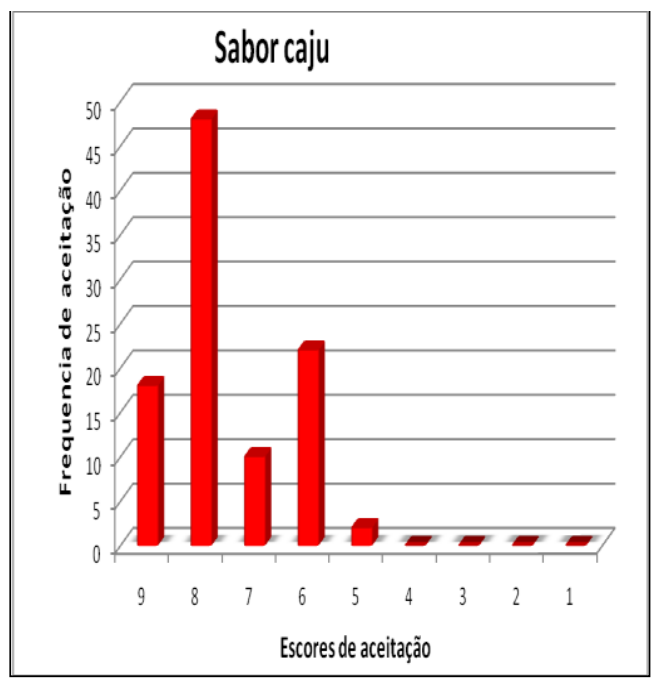

\section{Análise físico-química}

Foi possível quantificar os teores de ácido ascórbico, atividade de água e umidade e os valores encontrados podem ser observados na Tabela 2.

Tabela 2- Análise físico-química da barra de cereal de caju.

\begin{tabular}{cc}
\hline Determinação & Valor encontrado \\
\hline ÁCIDO ASCÓRBICO & $45,3 \pm 8,99 \mathrm{mg} / 100 \mathrm{~g}$ \\
ATIVIDADE DE ÁGUA & $0,59 \pm 0,01$ à $27,3^{\circ} \mathrm{C}$ \\
UMIDADE & $9,9 \pm 0,15 \%$ \\
\hline
\end{tabular}

*Cada valor foi obtido pela média \pm desvio padrão de triplicatas

$\mathrm{O}$ valor da atividade de água encontrado $(0,59)$ mostra que a barra produzida pode ser considerada um produto microbiologicamente seguro. Segundo FRANCO e LANGRAF (2008), considera-se o valor de 0,60 como o valor de atividade de água limitante para a multiplicação de qualquer microrganismo.

O teor de umidade encontrado $(9,9 \%)$ foi próximo ao encontrado por FREITAS e MORETTI (2007) e MATSUURA (2005) correspondentes a 10,7 \%, 8,0\%; superior ao encontrado por COELHO (2006) igual a 6,92\% e inferior ao encontrado por TORRES (2009) que foi 18,56\% para barra de cereal com pó de jaca e 23,46\% para barra de cereal com jenipapo seco. 
LIMA (2004), avaliando a barra de caju formulada em sua pesquisa encontrou $7,40 \%$ de umidade, uma atividade de água de 0,477 e 275,32 mg/100g de ácido ascórbico.

Os valores encontrados no presente trabalho de $9,9 \%, 0,59$ e 45,3 mg/100g para umidade, atividade de água e teor de ácido ascórbico, respectivamente, diferem dos encontrado por LIMA e, tais diferenças podem ser atribuídas às condições (tempo e temperatura) da secagem do caju e da fibra, ou ainda devido às diferentes proporções dos ingredientes na formulação.

BIDAISEE \& BADRIE (2001) citados por LIMA (2004), ao desidratar caju na forma de rodelas em soluções de sacarose de até $70^{\circ}$ Brix, com posterior secagem em estufa a $60^{\circ} \mathrm{C}$ por 48 horas, obtiveram produto com apenas $5,85 \mathrm{mg} / 100 \mathrm{~g}$ de ácido ascórbico. Este valor é muito inferior ao encontrado no presente trabalho. SOUZA E FILHO et al. (1999) relataram que as perdas de ácido ascórbico durante o processamento de caju estão associadas à combinação de perdas por difusão durante a osmose e à degradação química e física, pelo efeito do calor durante o tratamento térmico, tendo este, segundo os autores, maior efeito sobre a degradação da vitamina C.

A quantidade de ácido ascórbico (vitamina C) encontrada indica que a ingestão de uma barra de cereal de caju, ou seja, $25 \mathrm{~g}$ do produto, fornece $25 \%$ da Ingestão Diária Recomendada (IDR) de vitamina C para um adulto, que segundo a RDC $n^{\circ}$ 269/05, da ANVISA (Agência Nacional de Vigilância Sanitária), equivale a 45 mg de ácido ascórbico (FAO, 1998; BRASIL, 2005). Segundo a Resolução $n^{\circ}$ 27/98, da ANVISA o alimento para ser considerado como alto teor de vitaminas deve possuir no mínimo $30 \%$ da IDR de referência por 100g. Portanto, a barra de cereal de caju elaborado no presente trabalho pode ser considerada um alimento com alto teor de vitamina $\mathrm{C}$, por conter em sua formulação 45,3 mg de ácido ascórbico a cada 100g de barra (BRASIL, 1998).

\title{
4. Conclusão
}

A barra de cereal enriquecida com fibra de caju apresentou uma boa aceitação sensorial por parte dos provadores e suas características físico-químicas demonstram que é um alimento seguro microbiologicamente além de possuir alto teor de vitamina $\mathrm{C}$.

\begin{abstract}
The association of cereal bars with cashew apple has proved to be a innovative trends that aims to meet the market demand and avoid the waste of a fruit so nutritious. Therefore, the objective of this study was to develop and evaluate the sensory characteristics and physical-chemical one cereal bar enriched with cashew apple bagasse fiber. Through the acceptance tests can verify a good acceptability of the cashew apple bar from the majority of the judges, which proved to be likely to buy it. The physical-chemical analysis revealed that the cashew apple bar can be a food with high content in vitamin $C$. This fact is of great interest to the agricultural industries, as it opens up the possibility of a new product be launched in the consumer market, and ensure the use of cashew apple peduncle through a product with desirable nutritional and sensory characteristics.
\end{abstract}

Key-words: cereal bars, cashew apple, residue. 


\section{REFERÊNCIAS}

BRASIL. Ministério da Saúde. Agência Nacional de Vigilância Sanitária. Portaria no 27, de 13 de janeiro de 1998. Regulamento técnico referente à informação nutricional complementar. Diário Oficial da União, Brasília, 16 jan.1998.

BRASIL. Ministério da Saúde. Agência Nacional de Vigilância Sanitária. Resolução RDC n 269, de 22 de setembro de 2005. Aprova o regulamento técnico sobre a Ingestão Diária Recomendada (IDR) de proteína, vitaminas e minerais.

Diário Oficial da União, Brasília, 23 de setembro de 2005.

BUENO, R. O. G. Características de qualidade de biscoitos e barras de cereais ricos em fibra alimentar a partir de farinha de semente de nêspera. 2005. Tese (Mestrado em tecnologia de Alimentos)-Universidade Federal do Paraná, Curitiba (PR).

CARVALHO, M. G. Barras de cereais com amêndoas de chicha, sapucaia e castanha-do-gurguéia, complementadas com casca de abacaxi. 2008. Tese (Mestrado em Tecnologia de Alimentos) - Universidade Federal do Ceará, Fortaleza (CE).

COELHO, K. D. Desenvolvimento e avaliação da aceitação de cereais matinais e barras de cereais à base de amaranto (Amarantus cruentus L.). 2006. Tese (Mestrado em Nutrição Humana Aplicada) - Faculdade de Saúde Publica, Universidade de São Paulo (SP).

DUTCOSKY, S. D. Análise Sensorial de Alimentos. Curitiba: Editora Universitária Champagnat, 2. Ed. Revista e ampliada, 2007. 239 p.

FRANCO, B. D. G. M., LANDGRAF, M. Microbiologia dos Alimentos. São Paulo: Ed. Atheneu., 2008.

FREITAS, D. G.C.; MORETTI, R. H. Caracterização e avaliação sensorial de barra de cereais de elevado teor protéico e vitamínico. Ciência e Tecnologia de Alimentos, Campinas. abr.-jun. 2006.

GUTKOSKI L. C.; BONAMIGO, J. M. A.; TEIXEIRA, D. M. F.; PEDÓ I. Desenvolvimento de barra de cereais à base de aveia com alto teor de fibra alimentar. Ciência e Tecnologia de Alimentos, Campinas, v. 27, n. 2, p. 355-363, abr.jun. 2007. http://dx.doi.org/10.1590/S0101-20612007000200025

INSTITUTO ADOLPHO LUTZ. Normas analíticas do Instituto Adolfo Lutz: métodos químicos e físicos de análise de alimentos. 3.ed. São Paulo: Guanabara Dois, 1985.

Joint FAO/WHO Expert Consultation on Human Vitamin and Mineral Requirements (1998: Bangkok, Thailand). Vitamin and mineral requirements in human nutrition: report of a joint FAO/WHO expert consultation, Bangkok, Thailand, 21-30 September 1998.

KABORI, C. N.; JORGE, N. Caracterização dos óleos de algumas sementes de frutos como aproveitamento de resíduos industriais. Ciência Agrotécnica, Lavras, v. 29, n. 5, p. 1008-1014, set/out. 2005.

LIMA, Antônio Calixto. Estudo para a agregação de valor aos produtos de caju: elaboração de formulações de fruta e castanha em barra. 2004. Tese (Doutorado em Tecnologia de Alimentos) - Universidade Estadual de Campinas, Campinas (SP).

MATSUURA, F. C. A. U. Estudo do albedo de maracujá e de seu aproveitamento em barra de cereais. 2005. Tese (Doutorado em Tecnologia de Alimentos) - Universidade Estadual de Campinas, Campinas (SP).

OLIVEIRA, V. H. D.; ANDRADE, A. P. S. Produção integrada de caju. Abrindo portas para qualidade. Disponivel em: http://www.cnpat.embrapa.br/pif/artigos/agroanalyse/index.html. Acesso em: 20 jun. 2011.

PINHO, Lívia Xerez. Aproveitamento do resíduo do pendúnculo de caju (Anarcadium accidentale L.) para alimentação humana. 2009. Tese (Mestrado em Ciência e Tecnologia de Alimentos) - Universidade Federal do Ceará, Fortaleza (CE)

SILVA, I. Q. ; OLIVEIRA, B. C. F.; LOPES, A. S., PENA, R. S. Obtenção de barra de cereais adicionada do resíduo industrial de maracujá. Revista Alimentos e Nutrição. v.20, n.2, Araraquara. abr./jun. 2009. p. 321-329.

SOARES, Juarez Braga. O Caju: aspectos tecnológicos. Fortaleza: BNB, 1986. 256 p. 
SOUZA FILHO, M. S. M.; LIMA, J. R.; SOUZA, A. C. R.; SOUZA NETO, M. A.; COSTA, M. C. Efeito do branqueamento, processo osmótico, tratamento térmico e armazenamento na estabilidade da vitamina C de pedúnculos de caju processados por métodos combinados. Ciências e Tecnologia de Alimentos. Campinas, v. 19, n. 2, mai. 1999.

TORRES, E. R. Desenvolvimento de barras de cereais formuladas com ingredientes regionais. 2009. Tese (Mestrado em Engenharia de Processos) - Universidade Tiradentes, Aracaju (SE).

Submetido em 16 dez 2011, Aceito para publicação em 26 dez. 2012 